\title{
Análise do tempo de consolidação do sistema de plantio direto
}

\author{
Osvaldo C. Pereira Neto ${ }^{1}$, Maria de F. Guimarães ${ }^{1}$, Ricardo Ralisch ${ }^{1}$ \& Inês C. B. Fonseca ${ }^{1}$
}

\begin{abstract}
RESUMO
O sistema de plantio direto já está consagrado como sistema conservacionista de cultivo agrícola, o que motivou este trabalho, através do qual se visa analisar o tempo de consolidação deste sistema, considerando-se cultivos de milho com plantio direto implantado entre 2 e 14 anos. Esta análise foi feita por meio da medição da área das estruturas presentes no perfil cultural do solo com um SIG e, posteriormente avaliada pelo método estatístico de componentes principais. Constatou-se que as estruturas onde o plantio direto foi implantado há menos de 8 anos assemelharam-se às estruturas do sistema de plantio convencional, e quando implantado há mais de 9 anos, assemelharam-se às estruturas do perfil de floresta, concluindo-se que o período de consolidação do sistema de plantio direto situa-se entre o $9^{\circ}$ e o $10^{\circ}$ ano após a sua implantação, para as condições da área estudada. O excesso de detalhamento na nomenclatura das unidades morfologicamente homogêneas dificultou a análise dos dados.
\end{abstract}

Palavras-chave: geoprocessamento, análise de componentes principais, unidades morfologicamente homogêneas, ArcView, método do perfil cultural

\section{Analysis of consolidation time of no-tillage system}

\begin{abstract}
The no-tillage system has already been acclaimed as a conservational system of agricultural cultivation, what has motivated this work, through which it was aimed to analyze the consolidation time of this system, considering maize plantations with no-tillage system implemented between 2 to 14 years. This analysis has been done through the measuring of areas of the present structures in the cropping profile with GIS and later, evaluated by the statistical method of principal components. The structures where no-tillage system has been implemented for less than eight years are similar to conventional cultivation, and where it has been implemented for more than nine years are similar to forest cultivation, leading to the conclusion that the period of consolidation of no-tillage system is between the ninth and tenth year after its implementation, for the conditions of the analyzed area. The excess of details in the nomenclature of morphological homogeneous units makes the data analysis difficult.
\end{abstract}

Key words: geocoding, principal component analysis, morphological homogeneous units, ArcView, cropping profile method 


\section{INTRODUÇÃO}

Há milhares de anos a humanidade semeia e cultiva a terra, produzindo seu próprio alimento. Diversos sistemas de cultivo surgiram e desapareceram ao longo da história; atualmente, entretanto, apesar do pensamento agro-conservacionista, fruto de uma tentativa de resgate das injúrias impostas à natureza, o sistema de plantio direto tem forte penetração na produção agrícola, em contraposição ao chamado sistema convencional, ainda em uso.

O Sistema de Plantio Direto (SPD), segundo Seixas (2001), é um sistema de produção agrícola caracterizado por: a) manutenção da palhada deixada pela cultura anterior; b) aplicação de rotação de culturas; c) redução da taxa de mineralização da matéria orgânica; d) favorecimento da atividade biológica no controle de pragas e plantas daninhas; e) intensificação dos processos de agregação do solo.

Por impor menor revolvimento do solo durante o manejo agrícola, este sistema impacta menos o meio ambiente, através da redução do uso de combustível fóssil, minimizando os processos erosivos decorrentes da desestruturação física do solo.

A implantação do SPD nas áreas agrícolas do Brasil tem crescido muito na última década (FEBRAPDP, 2005), porém este sistema apresenta alguns impasses, ou seja, a mobilização reduzida do solo, aliada à sua maior umidade e o tráfego de máquinas agrícolas, mesmo pouco intenso, feito com máquinas de maior peso, fazem surgir áreas de compactação em superfície. Isso também ocorre no sistema de plantio convencional, em que o revolvimento do solo e o tráfego de máquinas são maiores, compactando camadas mais profundas do perfil; no entanto, essas camadas compactadas da superfície são rompidas no preparo do solo. Diversos trabalhos já discutiram e concluíram este fato por meio de análises de penetrometria (Oliveira, 1990; Silva et al., 2000; Albuquerque et al., 2001).

O “perfil do solo”, ou “perfil pedológico”, é amplamente conhecido na área agronômica, mas não deve ser confundido nem tomado como sinônimo do termo "perfil cultural do solo”. Manichon \& Gautronneau (1996) afirmam que as informações obtidas da interpretação de ambos diferem e não têm a mesma finalidade. Segundo esses autores, o perfil pedológico busca identificar os processos de formação dos solos a partir da rocha-mãe, mediante fatores bioclimáticos. O perfil cultural, por sua vez, é “o conjunto dos horizontes do solo individualizados pela intervenção de implementos agrícolas, pelo comportamento das raízes das plantas do local, pela influência dos fatores naturais (clima)” e pelas técnicas de cultivo adotadas.

O método do perfil cultural é usado no Brasil desde a década de 90 e permite destacar diferentes unidades morfológicas no perfil, conforme o manejo adotado. Com isso, pode-se entender e, conseqüentemente, intervir nos processos de compactação e selamento do solo, auxiliar na escolha da técnica de amostragem de solo mais apropriada, orientar a análise das interações bio-físico-químicas do solo, etc. (Tavares Filho et al., 1999; Fregonezi et al., 2001). O método apresenta boa correlação com as análises físicas realizadas em laboratório, como densidade global e porosidade (Neves et al., 2003).

Tamia et al. (1999) denominam as diferentes estruturas de um perfil cultural como sendo unidades morfologicamente homogêneas (UMH). Essas UMH's podem ser quantificadas pelo uso de Sistemas de Informação Geográfica (SIG), que são sistemas computacionais capazes de armazenar, recuperar, integrar, manipular e visualizar diferentes informações da superfície terrestre. Esses dados geográficos descrevem objetos do mundo real em termos de posicionamento com relação a um sistema de coordenadas (Burrough, 1986; Smith et al., 1987), razão por que esses sistemas podem ser utilizados em estudos relativos ao meio ambiente e aos recursos naturais, na pesquisa de previsão de determinados fenômenos ou no apoio às decisões de planejamento, considerandose o fato de que os dados armazenados representam um modelo do mundo real (Burrough, 1986).

Pereira Neto \& Guimarães (2005) utilizaram o SIG para propor um método de se quantificar áreas pequenas, como as unidades morfologicamente homogêneas (UMH) de um perfil cultural do solo, através do programa computacional ArcView v.8. As áreas das UMH's foram facilmente quantificadas por camadas de profundidade do solo.

O uso de SIG é uma realidade em nível mundial, em qualquer atividade na qual haja necessidade de se analisar, mapear e quantificar áreas. Inúmeros trabalhos surgem a cada dia nos quais se analisam aspectos diversos, tanto agronômicos quanto ambientais e urbanos, produzindo mapas de porções da superfície do planeta com temas variados, ou seja, mapas de uso do solo, de cobertura vegetal, de declividade, de ocupação urbana ou de qualquer outro que seja objeto de estudo.

Deste modo se levou a termo o presente trabalho, com o objetivo de verificar o tempo de consolidação do sistema de plantio direto ao longo de 14 anos de implantação, analisando-se a espacialização das unidades estruturais do solo; essas estruturas homogêneas do perfil de solo, nomeadas pelo método do perfil cultural, serão quantificadas a partir do uso de um SIG.

Pretende-se, então, chegar a um prazo de tempo aproximado em que o SPD estaria no início de sua consolidação. Até o presente momento, no entanto, não se encontrou, na literatura, uma metodologia que proponha tal objetivo. Esta proposta metodológica também vai ao encontro da necessidade de pesquisadores na área de conservação de solos e meio ambiente, de quantificar as estruturas homogêneas do perfil do solo, seja de forma relativa (percentual) ou absoluta (métrica).

\section{MATERIAL E MÉTODOS}

Os perfis do solo estudados se situam no município de Rio Verde, a sudoeste do Estado de Goiás, em uma área particular de produtores rurais. O clima é do tipo Aw (tropical de savana), segundo a classificação de Köeppen, com duas estações bem definidas: entre setembro e abril, a estação das chuvas, e entre maio e agosto, a estação da seca. O relevo da região varia de plano a suave ondulado, com pendentes 
longas, declividade em torno de 3\% e altitude média de $715 \mathrm{~m}$, sendo o solo classificado como Latossolo Vermelho Amarelo, textura argilosa.

Analisaram-se 8 sistemas de manejo do solo utilizando-se mapas de 12 perfis do solo na escala 1:10, os quais representavam as unidades morfologicamente homogêneas (UMH) de acordo com a metodologia do perfil cultural (Manichon \& Gautronneau, 1996), adaptada por Tavares Filho et al. (1999). Cada perfil, com 1,5 m de comprimento e 0,50 m de profundidade, representava as seguintes condições: a) um perfil em sistema de plantio convencional; b) dois perfis em SPD implantados há 2 anos; c) um perfil em SPD implantado há 5 anos; d) três perfis em SPD implantados há 8 anos; e) um perfil em SPD implantado há 11 anos; f) dois perfis em SPD implantados há 14 anos; g) um perfil em sistema de floresta e h) um perfil em sistema de pastagem.

Os perfis em SPD foram analisados durante o ciclo da cultura de milho e os perfis em sistema convencional, logo após o preparo do solo. As trincheiras foram abertas perpendicularmente à linha de preparo/plantio, em abril de 2004. As áreas apresentavam sistema de cultivo baseado no binômio milho/soja.

As UMH's são identificadas por letras. O arranjo das estruturas no perfil pode ser Livre (L), Contínuo (C), Laminar (Z) ou Fissurado (F). Representa-se a estrutura interna dos torrões por $\mu$ (poroso) e $\Delta$ (compacto), e os estados intermediários $(\Delta \mu, \Delta \mu / \mu$, etc $)$.

Como existem várias UMH's e não estão todas presentes em todos os perfis, agruparam-se as UMH's da seguinte maneira: $\mathrm{C} \mu$, contendo somente a unidade $\mathrm{C} \mu$; $\mathrm{C} \mu \mathrm{x}$, contendo qualquer variação de $\mathrm{C} \mu$, inclusive o $\mathrm{C} \Delta \mu / \mu$; $\mathrm{C} \Delta$, contendo somente a unidade $\mathrm{C} \Delta ; \mathrm{C} \Delta \mathrm{x}$, contendo qualquer variação de $\mathrm{C} \Delta$; Fx, contendo a unidade $\mathrm{F}$ e todas as suas variações; Lx, contendo a unidade L e as suas variações e Z, contendo a unidade $\mathrm{Z}$.

Os mapas dos perfis culturais do solo foram escaneados e importados para o software ArcView v.8.3, procedendo-se ao seu georreferenciamento, feito com pontos de controle situados nos quatro vértices do perfil, com unidade linear em centímetros (de 0 a $50 \mathrm{~cm}$ na altura do perfil e de 0 a $150 \mathrm{~cm}$ no seu comprimento).

Para cada perfil foram confeccionados três mapas, um com as UMH's do perfil, outro com as profundidades e o terceiro somente com o perímetro do perfil; este último serviu como molde para o recorte dos dois primeiros para que tivessem exatamente o mesmo tamanho. A seguir, fez-se a intersecção do mapa das UMH's com o das profundidades, obtendose um quarto mapa com as áreas de cada UMH por profundidade do perfil. As áreas dos polígonos foram calculadas para cada mapa $\left(\mathrm{em} \mathrm{cm}^{2}\right)$.

Com os valores das áreas desses polígonos utilizaram-se os métodos estatísticos "análise de componentes principais” e a "classificação hierárquica ascendente”, com a finalidade de agrupar os perfis do solo estatisticamente semelhantes; os referidos métodos estatísticos também foram usados por Fonseca \& Fonseca (2004). O software empregado foi o SPAD 3.5.

A análise de componentes principais, também conhecida como método de Karhunen-Loeve, se baseia na transforma- ção linear de "n” variáveis originais em " $n$ ” variáveis produzidas pelo sistema, em que a primeira variável produzida (primeira componente principal) tem a maior variação possível no conjunto de dados; a segunda indica a maior variação possível do restante, e assim por diante, até que 100\% da variação do conjunto estejam explicadas. Graficamente, diz-se que a rotação de pontos existentes em um espaço multidimensional origina eixos, denominados componentes principais que, dispostos em um espaço de duas dimensões, representam variabilidade suficiente que possa indicar algum padrão a ser interpretado (Tino, 2005).

O método hierárquico ascendente se inicia nominando-se tantos grupos quantos sejam os objetos de estudo (perfis de solo). Os objetos mais semelhantes vão sendo agrupados de conformidade com suas similaridades, até que todos tenham sido associados a outros objetos. Os resultados são mostrados na forma de um diagrama, denominado dendrograma em que, quanto mais semelhantes mais curtos são os ramos de ligação (Fonseca \& Fonseca, 2004).

\section{RESULTADOS E DISCUSSÃO}

Os mapas digitalizados são apresentados na Figura 1, com as linhas da "profundidade" sobrepostas ao tema "perfil".

Após as análises estatísticas, os agrupamentos obtidos pela classificação hierárquica não apresentaram tendência evolutiva da estruturação do solo. Na tentativa de se obter precisão no mapeamento das UMH's dos perfis, se excedeu a caracterização de unidades de transição, aumentando provavelmente, a subjetividade e, por conseqüência, diminuindo a precisão.

Procedeu-se, então, a um segundo agrupamento das UMH's diminuindo-se as suas variações: toda e qualquer unidade $\mathrm{C} \mu$ e variações foram unidas na unidade denominada $C \mu$ total e toda e qualquer unidade $C \Delta$ e variações foram unidas na unidade denominada $\mathrm{C} \Delta$ total; mantiveramse as unidades F, L e Z como planejado. Na Figura 2 se apresentam os resultados da quantificação das estruturas do perfil cultural após o segundo agrupamento das UMH's.

Com as análises estatísticas foi possível verificar a relação existente entre a área das UMH's e os perfis do solo e o agrupamento de perfis semelhantes. Para os perfis avaliados por inteiro, ou seja, sem se levar em consideração os níveis de profundidade, a combinação linear dos valores das áreas das UMH's (chamada primeira componente principal) explicou $62,53 \%$ da variabilidade dos dados; o segundo componente principal explicou 34,82\%; portanto, esses dois eixos representaram 97,35\% da variância total. O terceiro componente principal explicou somente 2,65\%, totalizando $100 \%$ (Figura 3).

Esses eixos fatoriais formam um espaço onde se indicam: a) os perfis, representados por pontos dispersos nesse espaço, sendo que, quanto mais próximos os pontos estiverem entre si maior a semelhança dos valores da UMH's desses perfis; b) as UMH's, por meio de vetores; o ângulo que os vetores formam entre si representa a correlação entre as UMH's, ou seja, quanto menor o ângulo maior a correlação. 
PERFIL 1 - PC

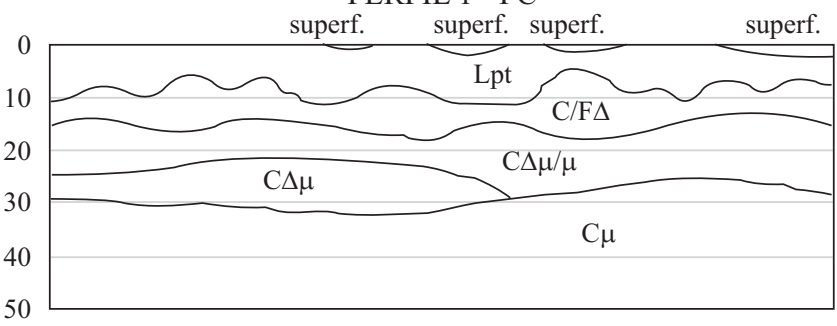

PERFIL 3 - PD2anos

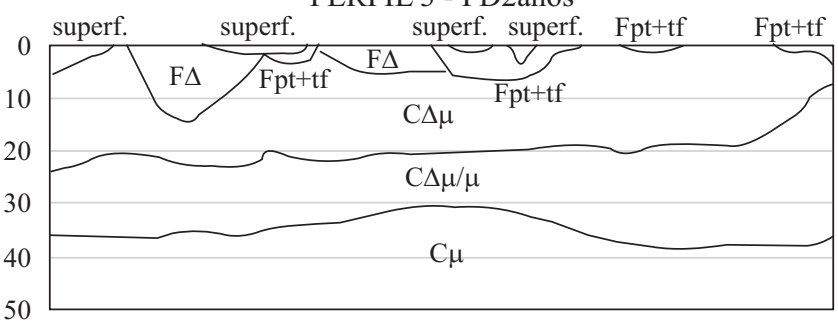

PERFIL 5 - PD8anos

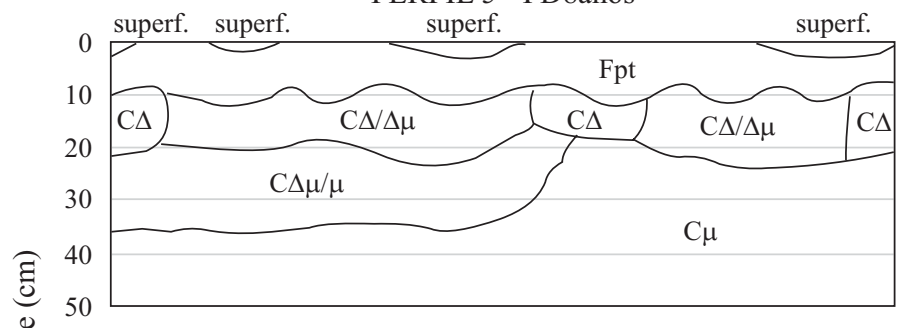

PERFIL 7 - PD8anos superf.

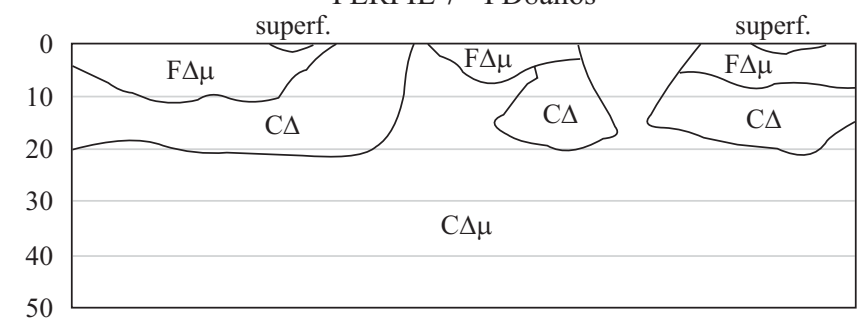

PERFIL 9 - PD14anos

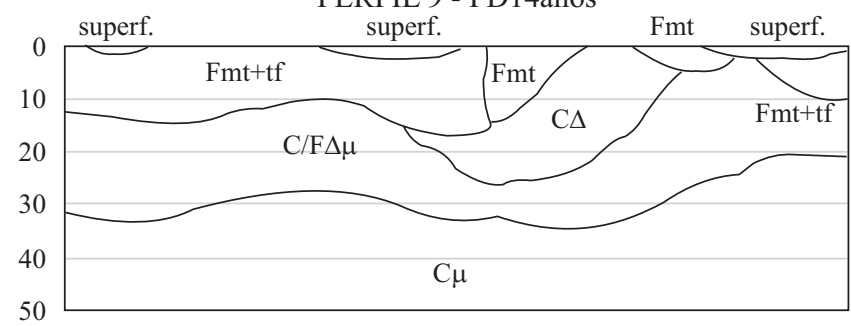

PERFIL 11 - Floresta

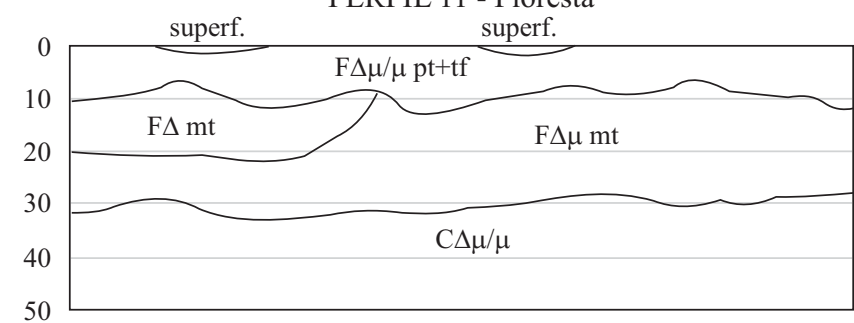

PERFIL 2 - PD2anos

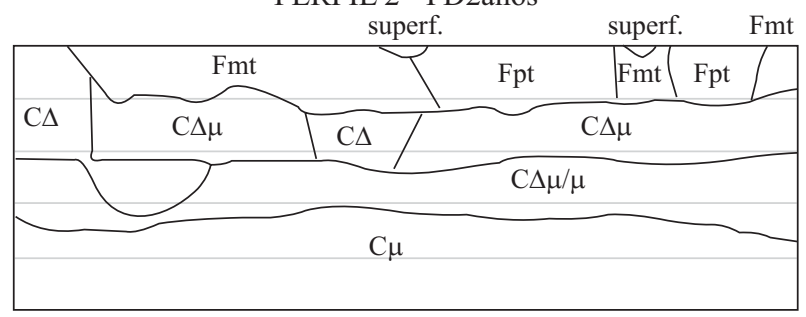

PERFIL 4 - PD5anos

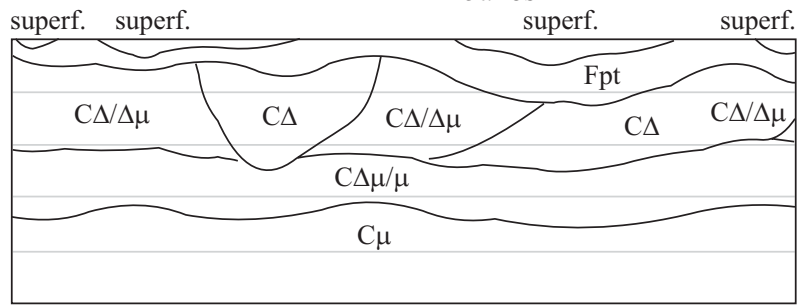

PERFIL 6 - PD8anos

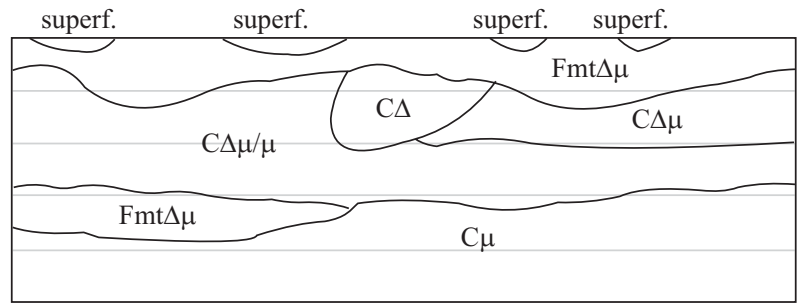

PERFIL 8 - PD11anos

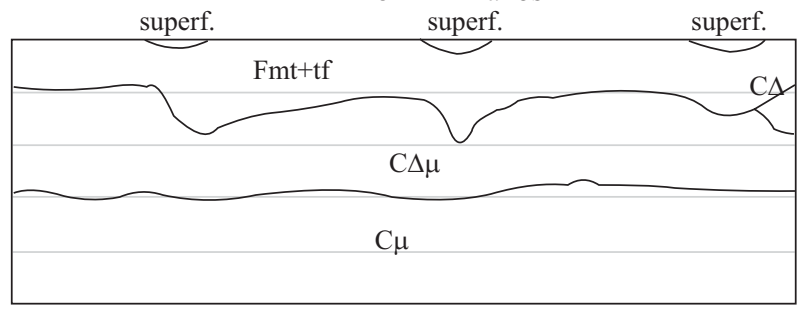

PERFIL 10 - PD14anos

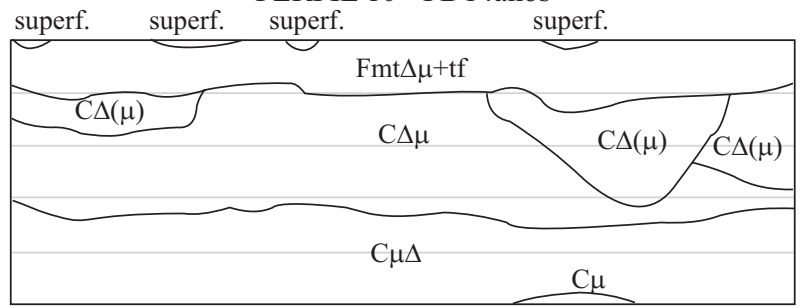

PERFIL 12 - Pastagem

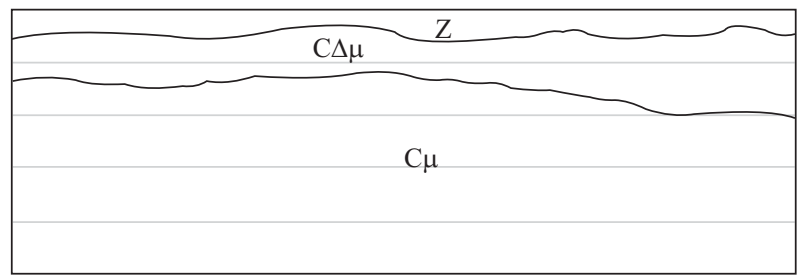

Figura 1. Perfis culturais utilizados; $(\mathrm{PC}=$ plantio convencional; $\mathrm{PD}=$ plantio direto; $\mathrm{F}$ ou $\mathrm{C}=$ volume de solo Fissural ou Contínuo; $\Delta$ ou $\mu=$ torrões compactos ou porosos; $\mathrm{pt}, \mathrm{mt}, \mathrm{gt}=$ pequenos, médios ou grandes torrões; $\mathrm{tf}=$ terra fina; $\mathrm{L}=$ solo pulverizado; $\mathrm{Z}=$ estrutura laminar; $\mathrm{o}$ sinal "I" representa transição e "()" representa traços) 


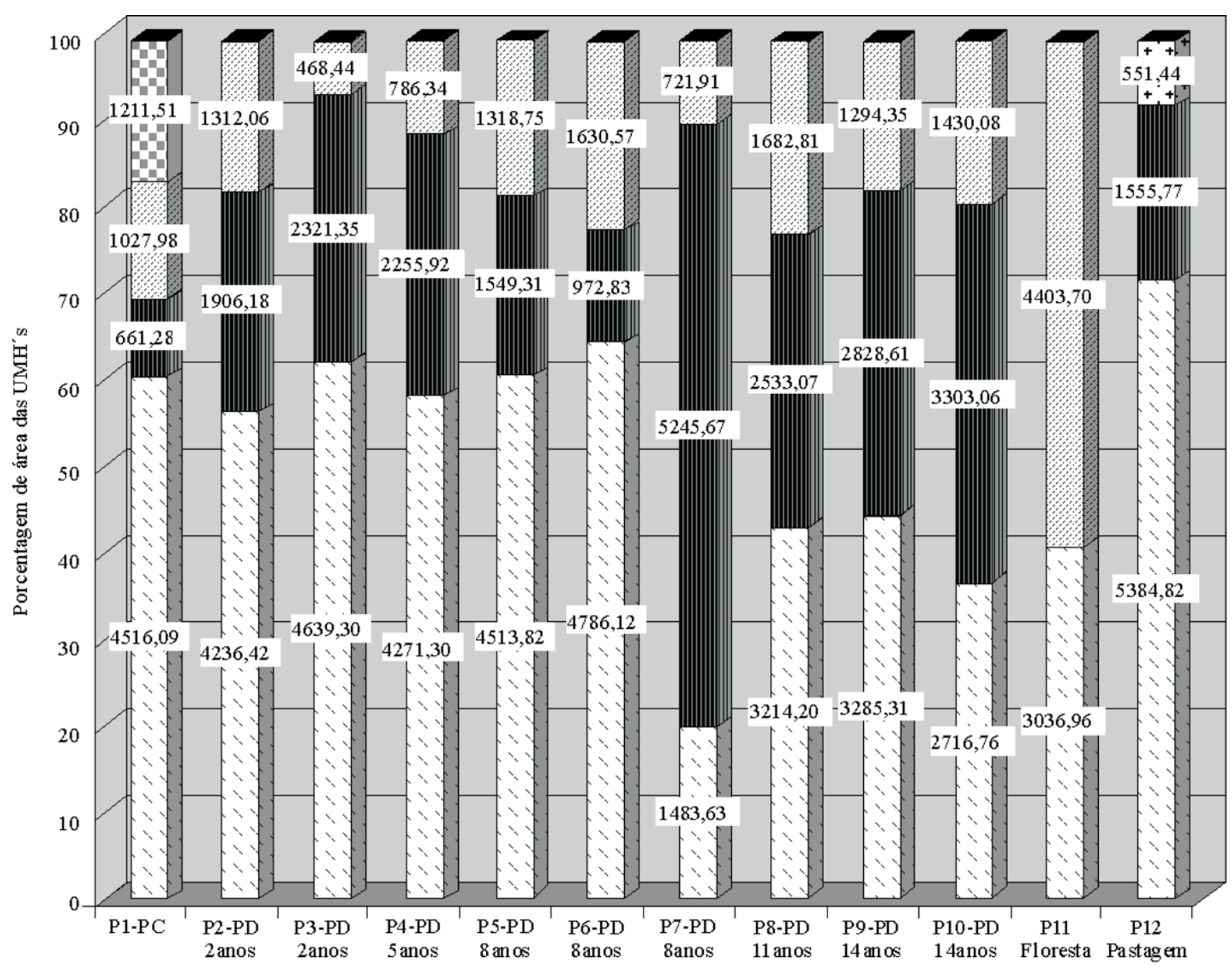

Perfis analisados

\begin{tabular}{|c|}
\hline UMH's: \\
\hline
\end{tabular}

Figura 2. Área $\left(\mathrm{em}^{2} \mathrm{~cm}^{2}\right.$ e porcentagem das $\mathrm{UMH}^{\prime} \mathrm{s}$ nos perfis analisados (PC = plantio convencional; $\mathrm{PD}$ = plantio direto)

A classificação hierárquica ascendente foi realizada utilizando-se os 3 eixos fatoriais (Figura 4). Por meio da observação do dendrograma, nota-se que o classificador separou os perfis em dois grandes grupos, representados pelos dois ramais à esquerda da figura, na qual os perfis com SPD implantado há 8 anos ou menos, ficaram agrupados com o perfil do sistema convencional e os perfis com mais de 8 anos de SPD permaneceram agrupados com o perfil de floresta indicando a tendência conservacionista da implantação do SPD na estruturação física do solo, ratificando a importância desse sistema para o meio ambiente.

Dos três perfis em plantio direto há 8 anos, dois se agruparam com o perfil do sistema convencional e um ficou com o perfil de floresta. Aqueles que permaneceram com o sistema convencional são perfis da mesma trincheira e, portanto, semelhantes, enquanto o que ficou com o perfil de floresta estava sob uma área de experimento de milho já colhido e bastante invadido por plantas daninhas. Neste, o manejo agrícola pode, possivelmente, ter resultado em uma característica estrutural do solo diferente de seus pares com 8 anos; além disso, o aparente abandono da área e o surgimento de várias plantas invasoras podem ter mantido o perfil com característica mais semelhante ao perfil de floresta.

Ainda pensando nessa distinção, apresenta-se uma sugestão técnica de que este seja o limite cronológico de implantação/ consolidação do SPD nessas condições ambientais, ou seja, após 8 anos de implantação do SPD este tomará as condições e características estruturais do solo mais próximas às condições encontradas em um perfil de floresta. Outros trabalhos poderiam ser feitos com o objetivo de monitorar anualmente as UMH's nos perfis com tempo de implantação do SPD mais recentes.

Partindo-se para uma análise do perfil por nível de profundidade não se percebe, na profundidade de zero a $10 \mathrm{~cm}$, qualquer coerência nos agrupamentos estatísticos; por se tratar de uma camada diretamente atingida por toda e qualquer ação antrópica ou natural, sua dinâmica estrutural pode ser 


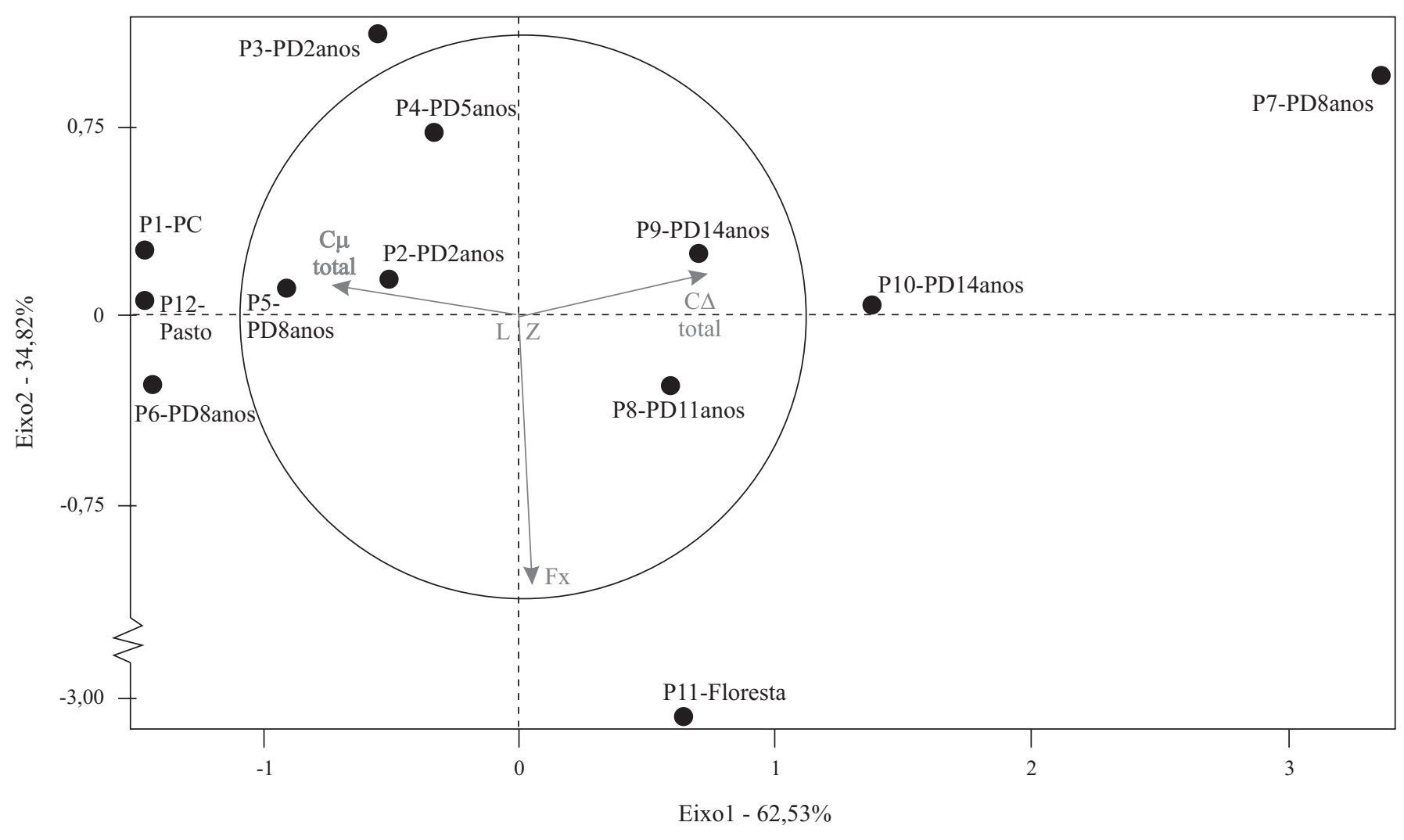

Figura 3. Análise de componentes principais para todo o perfil. Plantio convencional (PC) e direto (PD); volume de solo Fissural (F), Contínuo (C), Livre (L) e Laminar (Z); torrões compactos $(\Delta)$ e porosos $(\mu)$

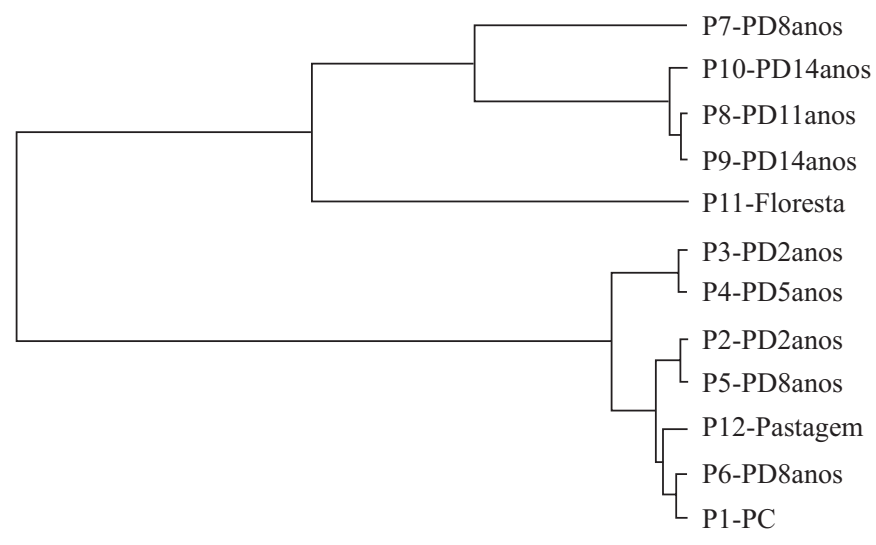

Figura 4. Classificação hierárquica ascendente aplicada ao perfil todo. Plantio convencional (PC) e direto (PD)

grande, não demonstrando tendência alguma com a cronologia de implantação do SPD.

Na profundidade de 10 a $20 \mathrm{~cm}$ também não se consegue visualizar tendência cronológica de implantação do SPD (Figura 5A), mas se observa que o perfil de floresta se assemelha ao do sistema convencional, o que não encontra respaldo na ciência do solo. Contudo, no solo analisado, ocorre um adensamento natural em sub-superfície (Oliveira, 1990; Silva et al., 2000; Albuquerque et al., 2001), que o método estatístico pode estar quantitativamente relacionando com o adensamento antrópico do sistema convencional.

Na profundidade de 20 a $30 \mathrm{~cm}$, o dendrograma produzido (Figura 5B) se assemelha ao da análise do perfil como um todo, com os mesmos dois agrupamentos, juntando os perfis de SPD mais antigos ao perfil de floresta e os perfis de SPD mais novos ao sistema convencional. Esta camada de profundidade seria o limite divisório entre a ação antrópica dos implementos agrícolas e as camadas mais inferiores não mobilizadas, fato que poderia ser monitorado continuamente em perfis para se verificar a veracidade dessa tendência visto que, caso se confirme, a metodologia do trabalho para analisar o tempo de consolidação do SPD poderá ser feita somente com as medidas das UMH's na profundidade de 20 a $30 \mathrm{~cm}$, ao invés do perfil todo, poupando tempo e recursos.

Nas demais profundidades (30 a $40 \mathrm{~cm}$ e de 40 a $50 \mathrm{~cm}$ ), nota-se claramente que o formato do dendrograma mudou não havendo, portanto, nenhum agrupamento mas apenas uma seqüência de semelhanças (Figura 5C e 5D), evidenciando que as profundidades não foram alteradas pelo manejo agrícola, permanecendo a estrutura $\mathrm{C} \mu$, que corresponde ao Bw dos latossolos.

Os trabalhos científicos em que se utiliza o método do perfil cultural, apresentam descrições feitas a partir de análises físico-químicas do solo e/ou de observações morfológicas realizadas no perfil (Fregonezi et al., 2001, Muller et al., 2001). As descrições oriundas dessas análises físico-químicas são precisas e objetivas; já as descrições emitidas a partir das observações do perfil carregam, por parte de alguns autores, o conceito informal de que o método do perfil cultural é subjetivo. Neste trabalho foram manuseadas, como dado principal, exatamente as UMH's identificadas no perfil. Se essas UMH’s e suas respectivas áreas apresentaram 
A.

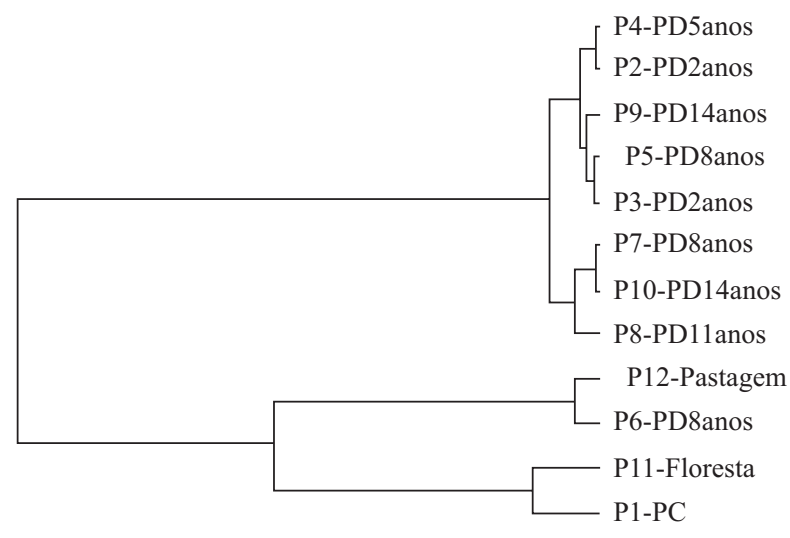

B.

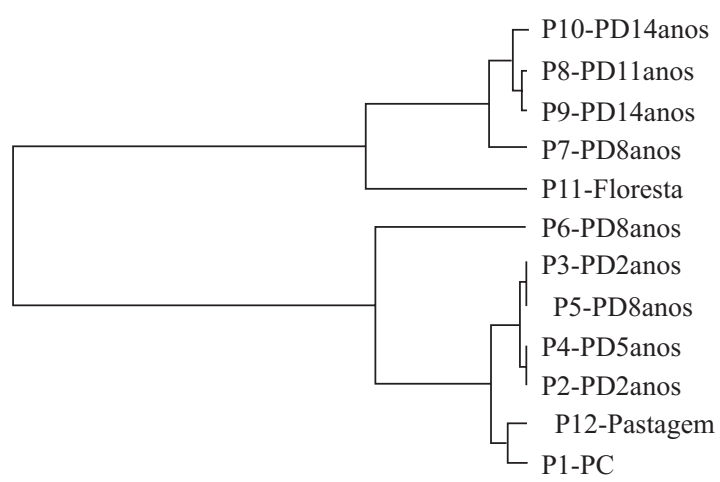

C.

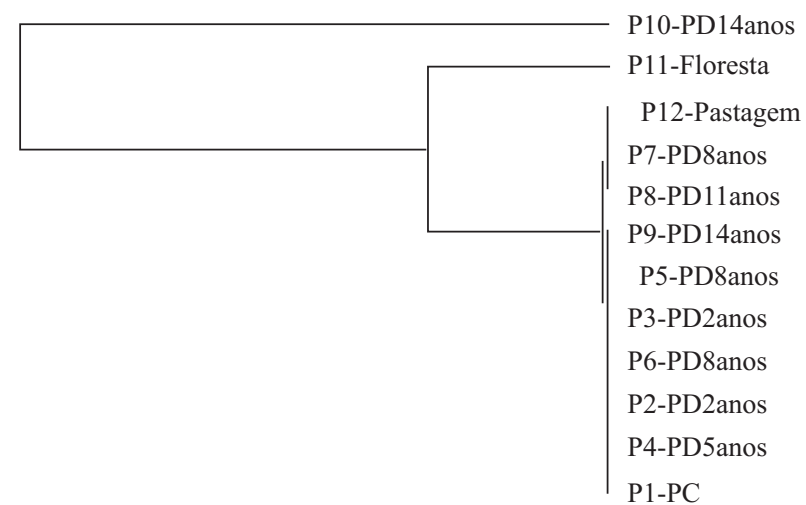

D.

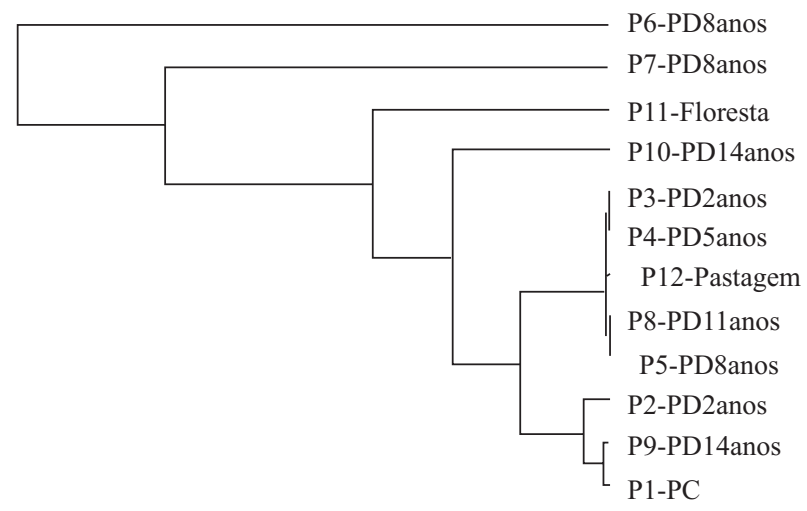

Figura 5. Classificação hierárquica ascendente aplicada à profundidade: (A) de 10 a $20 \mathrm{~cm}$; (B) de 20 a $30 \mathrm{~cm}$; (C) de 30 a $40 \mathrm{~cm}$; (D) de 40 a $50 \mathrm{~cm}$. Plantio convencional (PC) e direto (PD)

resultado lógico, significa que se pode retificar a idéia da subjetividade do método.

\section{CONCLUSÕES}

1. Para o local de estudo, nas condições ambientais existentes, o SPD se mostra consolidado aproximadamente entre o $9^{\circ}$ e o $10^{\circ}$ ano de sua implantação.

2. A metodologia proposta mostrou-se válida e adequada para quantificar estruturas homogêneas de um perfil cultural conhecido.

3. O método utilizado permitiu quantificar um dado qualitativo, possibilitando analisar, matematicamente, um conjunto de dados oriundos de observações de caráter subjetivo.

4. O excesso de detalhamento na discriminação das UMH's foi o fator que prejudicou a observação da tendência dos resultados.

5. A nomenclatura mais abrangente auxiliou a diminuição da subjetividade do método do perfil cultural defendida informalmente por alguns pesquisadores.

\section{AGRADECIMENTOS}

Ao Dr. Eric Scopel e Jean-Marie Douzet do CIRAD pela disponibilização do campo experimental, discussão dos resultados e apoio logístico de campo, deslocamento e estadia.

\section{LITERATURA CITADA}

Albuquerque, J. A.; Sangoi, L.; Ender, M. Efeitos da integração lavoura-pecuária nas propriedades físicas do solo e características da cultura do milho. Revista Brasileira de Ciência do Solo, Viçosa, v.25, p.717-723, 2001.

Burrough, P. A. Principles of geographical information system for land resources assessment. 1.ed. New York: Oxford University Press, 1986. 193p.

FEBRAPDP - Federação Brasileira de Plantio Direto na Palha. Área de plantio direto no Brasil. http://www.febrapdp.org.br/ br\%20evolucao\%20pd\%2093-04.html. 11 Out. 2005.

Fonseca, R. C. B.; Fonseca, I. C. B. Utilização de métodos estatísticos multivariados na caracterização do mosaico sucessional em floresta semidecídual. Revista Árvore, Viçosa, v.28, n.3, p.351-359, 2004.

Fregonezi, G. A. F.; Brossard, M.; Guimarães, M. F.; Medina, C. C. Modificações morfológicas e físicas de um latossolo argiloso sob pastagens. Revista Brasileira de Ciência do Solo, Viçosa, n.25, p.1017-1027, 2001.

Manichon, H.; Gautronneau, Y. Guía metódica del perfil cultural - Informe 54. La Paz: IBTA/ORSTOM, 1996. 29p. 
Muller, M. M. L.; Guimarães, M. F.; Desjardins, T.; Martins, P. F. S. Degradação de pastagens na Região Amazônica: Propriedades físicas do solo e crescimento de raízes. Pesquisa Agropecuária Brasileira, Brasília, v.36, n.11, p.1409-1418, 2001.

Neves, C. S. V. J.; Feller, C.; Guimarães, M. F.; Medina, C. C.; Tavares Filho, J.; Fortier, M. Soil bulk density and porosity of homogeneous morphological units identified by the cropping profile method in clayey Oxisols in Brazil. Soil and Tillage Research, Amsterdam, The Netherlands, v.71, n.2, p.109-119, 2003.

Oliveira, L. B. O estudo físico do solo e a aplicação racional de técnicas conservacionistas. Pesquisa Agropecuária Brasileira, Brasília, v.2, p.281-285, 1990.

Pereira Neto, O. C.; Guimarães, M. F. Método para quantificar pequenas áreas (perfil do solo) utilizando SIG. Revista Semina-Agrárias, Londrina, v.26, n.4, p.495-500, 2005.

Seixas, J. Níveis de compactação do solo na cultura do milho (Zea Mays L.). Curitiba: UFPR, 2001. 80p. Dissertação Mestrado
Silva, V. R.; Reinert, D. J.; Reichert, J. M. Resistência mecânica do solo à penetração influenciada pelo tráfego de uma colhedora em dois sistemas de manejo do solo. Ciência Rural, Santa Maria, v.30, p.795-801, 2000.

Smith, T. R.; Menon, S.; Star, L. J.; Estes, E. J. Requirements and principles for the implementation and construction of large-scale geographic information system. Inter-national Journal of Geographical Information System, London, v.1, n.1, p.13-21, 1987.

Tamia, A.; Moreau, R.; Fortier, M.; Yoro G. Influence du travail du sol sur l'évolution physique d'un sol forestier ferrallitique après défrichement motorisé. Étude et Gestion des Soils, Orleans, França, v.6, n.1, p.27-39, 1999.

Tavares Filho, J.; Ralisch, R.; Guimarães, M. F.; Medina, C. C.; Balbino, L. C.; Neves, C. S. V. J. Método do perfil cultural para avaliação do estado físico de solos em condições tropicais. Revista Brasileira de Ciência do Solo, Viçosa, v.23, p.393-399, 1999.

Tino, V. F. Utilização da análise de componentes principais para a regulagem de máquinas de injeção plástica. Rio de Janeiro: UFRJ, 2005. 110p. Dissertação Mestrado 